\title{
THE IMPACT OF COEFFICIENT DRIFT AND MEASUREMENT ERROR ON THE ACCURACY OF RATIO-CORRELATION POPULATION ESTIMATES
}

\author{
Jeff Tayman and Edward Schafer*
}

\begin{abstract}
Temporal instability of the regression coefficients (coefficient drift) is considered by many to be the primary source of error in population estimates produced with the ratio-correlation technique. While numerous approaches have been proposed to deal with this problem, improvements in estimate accuracy have been minimal and the degree of error due to coefficient drift has not been well documented. Moreover, little attention has been given to other potential sources of error in this method. Six tests of the ratio model are developed using estimated and actual symptomatic indicators in combination with models based on the 1960-70 and 1970-80 decades. Comparisons of the six tests with 1980 census counts, for the state of Washington, show that coefficient drift has only a minor impact on estimate accuracy. Furthermore, it has considerably less influence than poorly measured symptomatic variables.
\end{abstract}

\section{Introduction}

Recent years have seen a tremendous increase in the number of governmental agencies, private firms and university departments producing postcensal (current) population estimates. While these efforts represent significant time and resource allocations, the value of population estimates far outweigh the cost of developing them. Administrative and planning programs, at all levels of government, require

\footnotetext{
* San Diego Association of Governments and Center for Population Research and Census, Portland State University. The authors are grateful to Theresa Lowe and the late John Walker for providing the data for this study and to David Swanson for his comments on an earlier draft of the paper. They also thank the anonymous referees for their helpful suggestions. An earlier version of this paper was presented at the annual meeting of the Population Association of America, San Diego, California, March 1982.
}

current updates of population. One of the more important uses, in this context, is in the allocation of federal and state general revenue sharing and other funds to counties and cities. Private sector decisions concerning sales markets, site locations, product demands, etc., often rely on population estimates. Evaluation of demographic forecasts are frequently based on current trends in population. In addition, these data are an integral part of many research projects not only in demography but in virtually all social science disciplines (e.g. Espenshade and Tayman, 1982; Sly and Tayman, 1980).

Comparative analyses have shown the ratio correlation technique, introduced by Schmitt and Crosetti (1954), to be one of the most accurate and widely used methods for producing postcensal population estimates (Serow and Martin, 1978; U.S. Bureau of the Census, 1973; Goldberg, Rao and Namboodiri, 1964; Zitter and Shryock, 1964; Goldberg and Balakrishnan, 1960). This is an allocation procedure based on the relationships between changes in the relative size of the population and changes in the relative size of one or more symptomatic indicators (e.g., voter registration, school enrollments). Most applications of the ratiocorrelation model involve the allocation of state population estimates to counties, although this method can be applied to any nested geographic system. An estimating equation is developed from a time period (usually two decennial censuses) that precedes the date of the estimate. The allocation proportions are determined by solving the equation using relative counts of the symptomatic indicators at the time of estimation. The key assumption of the method is that the relationships of the estimating equation will continue into the postcensal period.

The violation of this assumption is thought to be the primary source of error in this method (Ericksen, 1974; Namboodiri, 1972), and most refinements to the ratio-correlation model have focused on ways to minimize the temporal instability (coefficient drift) of the regression 
coefficients. O'Hare (1980) noted that additional improvements in ratio-correlation estimates are unlikely to occur until means of measuring and adjusting for coefficient drift in regression techniques are developed. For instance, data augmentation has been discussed by Pursell (1970) and Rosenberg (1968); postcensal sample survey data by Bousfield (1977) and Ericksen (1973); averaging univariate models by Namboodiri and Lalu (1971); ridge-regression by D'allesandro and Tayman (1981), Spar and Martin (1979) and Swanson (1978a); causal modeling principles by Swanson (1980); and variable transformations by Swanson and Tedrow (1984), O'Hare (1976) and Schmitt and Grier (1966).

Improvements in estimate accuracy produced by these refinements have not been uniformly significant. For example, a recent study showed that a logarithmic transformation of the ratio variables produced 1970 population estimates for the counties in Washington state which had almost the identical error as estimates prepared by the ratio-correlation method (i.e., 5.062 percent versus 5.068 percent) (Swanson and Tedrow, 1984). However, using enrollment as the dependent variable, the same study found that significant improvements were obtained using a logarithmic transformation. Mandell and Tayman (1982) examined the relationship between the extent of coefficient drift and estimate error in 16 ratio-correlation and difference-correlation models for counties in Florida. These results indicated that while coefficient drift did have some direct impact on estimate accuracy, its influence was not as pervasive as suggested in the literature. They concluded that the issue of coefficient drift cannot be evaluated independently of other potential sources of estimate error.

There are two additional causes of error inherent in the ratio-correlation model which have received virtually no systematic attention; namely, random error not explained by the symptomatic indicators, and measurement error in the symptomatic data. ${ }^{1}$ Error due to unexplained variance is not likely to have a significant impact on estimate accuracy. The $R^{2} \mathbf{s}$ in virtually all equations are extremely high (i.e., above .95). Only a small amount of the variance in the population ratios is not accounted for by the symptomatic indicators. More important is that the relative magnitude of $\mathrm{R}^{2}$ has not been found to be a good predictor of estimate accuracy (Mandell and Tayman, 1982; D'allesandro and Tayman, 1981; Swanson, 1981; Spar and Martin, 1979.)

Measurement error can impact the accuracy of ratio-correlation estimates in two ways. Poorly measured explanatory variables result in biased and inconsistent Ordinary Least Squares estimates of the regression coefficients, because the assumption of zero correlation between the explanatory variable and disturbance term no longer holds. (A detailed proof is found in Kmenta, 1971, pp. 307-309). An equation with biased coefficients could introduce additional error into the estimates. Postcensal symptomatic indicators which are imperfectly measured or lagged also contribute to estimate error. Disturbances in these variables are transmitted directly to the population estimate; therefore, this source of error may be more significant than the error due to biased coefficients in the estimating equation.

The purpose of this report is to examine the relative impacts of measurement error and coefficient drift on estimates produced by the ratio-correlation technqiue. It extends previous studies by showing the exact increase in estimate error which is due to coefficient drift. In addition, to make a precise determination of its impact on estimate accuracy, a method is offered for introducing measurement error into the symptomatic indicators.

\section{Data and Methods}

The analysis involves comparisons between 1980 federal census counts and total population estimates for the 39 counties in Washington state. These estimates are developed from a ratio-correlation model using the following symptomatic (independent) variables: registered voters, school enrollment (grades 1-8) and total employment (less domestic and self-employed workers). Total population is the dependent variable. Six different estimation tests, created by varying the decade of estimation (1960-70 and 1970-80) and by using either actual or estimated symptomatic indicators, are shown in Table 1. Three regression equations denoted as Models I, II and III in the table are used to generate the six tests. 
The Impact of Coefficient Drift and Measurement Error

on the Accuracy of Ratio-Correlation Population Estimates

Table 1

Six Test Specifications

of Three Ratio-Correlation Models ${ }^{\mathrm{a}}$

\begin{tabular}{|c|c|c|c|}
\hline & Model I & Model II & Model III \\
\hline $\begin{array}{l}1980^{\mathrm{b}} \\
\text { Postcensal } \\
\text { Symptomatic } \\
\text { Indicators }\end{array}$ & $\begin{array}{c}1970-80 \\
\text { True } \\
\text { Symptomatic } \\
\text { Indicators }\end{array}$ & $\begin{array}{c}1970-80 \\
1970 \text { Symptomatic } \\
\text { Indicators Estimated }\end{array}$ & $\begin{array}{c}\text { 1960-70 } \\
\text { True } \\
\text { Symptomatic } \\
\text { Indicators }\end{array}$ \\
\hline $\begin{array}{l}\text { True } \\
\text { Estimated }\end{array}$ & $\begin{array}{l}\text { Test I } \\
\text { Test II }\end{array}$ & $\begin{array}{l}\text { Test III } \\
\text { Test IV }\end{array}$ & $\begin{array}{l}\text { Test V } \\
\text { Test VI }\end{array}$ \\
\hline
\end{tabular}

The ratio correlation equation is defined as:

$$
\begin{aligned}
& {\left[\left(P_{i}^{t} / P^{t}\right) /\left(P_{i}^{0} / P^{0}\right)\right]=a+\sum b_{k} *\left[\left(X_{i k}^{t} / X_{k}^{t}\right) /\left(X_{i k} / X_{k}^{0}\right)\right]+E} \\
& \text { where, } 0 \text { = prior census; } \\
& t \text { = most current census; } \\
& P_{i}=\text { population living in county } i \text {; } \\
& \mathbf{P}=\text { population living in the state; } \\
& \mathrm{X}_{\mathrm{ik}}=\text { count of the kth symptomatic indicator in county } \mathrm{i}_{\text {; }} \\
& \mathrm{X}_{\mathrm{k}}=\text { count of the } \mathrm{kth} \text { symptomatic indicator in the state; and } \\
& \mathbf{E}^{\mathbf{2}}=\text { random error term. }
\end{aligned}
$$

b Nineteen-eighty represents the postcensal time point or estimate year; therefore, the equation based on the 1970-80 decade encompasses the postcensal time point. The fact that the 1970-80 equation is developed from true symptomatic indicators is unrelated to the operation of solving for the population estimates by substituting estimated postcensal (1980) symptomatic data into the equation (Test II).

Test $I$ is the standard for comparison since it contains neither coefficient drift nor measurement error. Coefficient drift is eliminated by producing estimates for the last time point (1980) over which the model is calibrated (1970-80). Tests II, III and IV examine the two impacts of poorly measured symptomatic indicators. They control for coefficient drift by using the 1970-80 time period to estimate the regression coefficients. Test II looks at measurement error in the postcensal symptomatic indicators. Test III examines the influence of specification bias on the population estimates by using an equation generated from estimated symptomatic indicators (1970 only). Test IV portrays the joint impact of measurement error in the estimating equation and in the postcensal symptomatic data. Coefficient drift is introduced in Test V, since the equation is based on information that precedes the date of the population estimate by 10 and 20 years (1960-70 decade). This model controls for measurement error, as all data represent their "true" values. Finally, Test VI illustrates the combined effects of coefficient drift and postcensal symptomatic data measurement error.
Measurement error is introduced into all three symptomatic indicators for 1970 and 1980. This is accomplished by using estimates derived from ratio-correlation equations. Separate estimating equations are developed for each symptomatic indicator. All equations use occupied housing units as the independent variable. The 1970 and 1980 estimates for the symptomatic variables are derived from equations calibrated from 1960-70 and 1970-80 data sets, respectively. The measurement error is considered to be random, since these estimates are based on a model which contains a random disturbance (error) term with the following assumed characteristics: normal distribution, mean $=0$, constant variance and no correlation between themselves or with the independent variables (Blalock, 1972, pp. 362-372). ${ }^{2}$

Plots of the residuals and the independent variable in each equation (Beasley, Kuh and Welsch, 1980, Chapter 2; Chatterjee and Price, 1977, pp. 9-10; Anscombe and Tukey, 1963) are used to test for heteroscedasticity, residual outliers and for possible model misspecification. In addition, a quantitative measure of 
Table 2

Measures of Error for the Estimated Symptomatic Indicators $1970,1980^{a}$

\begin{tabular}{lcccccc}
\hline \hline $\begin{array}{l}\text { Error } \\
\text { Measures }\end{array}$ & Voters & Enrollment & Employment & Voters & Enrollment & Employment \\
\hline $\begin{array}{l}\text { AAPEb } \\
\text { " Errors }\end{array}$ & 5.757 & 9.639 & 19.373 & 6.134 & 8.294 & 13.798 \\
$\begin{array}{l}>5 \% \\
\text { \# Errors }\end{array}$ & 19 & 29 & 24 & 20 & 30 & 31 \\
$>10 \%$ & 6 & 12 & 18 & 6 & 12 & 18 \\
R-squared & .927 & .907 & .646 & .847 & .859 & .678 \\
\hline \hline
\end{tabular}

aError is the difference between the reported data and estimated values.

${ }^{b}$ Average Absolute Percent Error.

cExplained variance for each estimation equation.

heteroscedasticity, the Park (1966) test is computed. This procedure involves a double-log regression of the independent variable on the squared residuals (Gujarati, 1978, pp. 202205; Goldfield and Quandt, 1972, Chapter 3). The assumption of normally distributed disturbances is examined by plotting the residuals on normal probability paper (Draper and Smith, 1981, pp. 177-183). No apparent violations of the residual assumptions are found when these procedures are applied. ${ }^{3}$ Table 2 shows the degree of error introduced into each symptomatic indicator.

\section{Analysis}

Table 3 presents statistics of the three models described in Table 1.4 The extent of coefficient drift can be seen by comparing Models I and III, since the identical equation specification has been generated for both a prior and current decade. There appears to be a sizable amount of coefficient drift. While the coefficient for enrollment remains relatively constant, the coefficients for voters and employment change considerably. Application of the Chow test confirms that the set of coefficients between the 1960-70 and 1970-80 decades are different at the .05 level of significance (Chow, 1960). While this finding could be a result of the particular time periods, variables selected and universe studied, Mandell and Tayman (1982), using the same test, found significant levels of coefficient drift in all $16 \mathrm{ratio} /$ difference models for the periods 1950-60 and 1960-70.

Table 3

Regression Results of the Three Alternative Ratio-Correlation Models

\begin{tabular}{|c|c|c|c|c|c|}
\hline \multicolumn{6}{|c|}{ Unstandardized Coefficients } \\
\hline Equations & Voters & Enrollment & Employment & Intercept & $R^{2}$ \\
\hline \multicolumn{6}{|l|}{ Model I } \\
\hline $\begin{array}{l}1970-80 \\
\text { No Error }\end{array}$ & $\begin{array}{r}.37678 \\
(.06921)\end{array}$ & $\begin{array}{r}.45827 \\
(.07461)\end{array}$ & $\begin{array}{r}.19285 \\
(.05641)\end{array}$ & -.02805 & .937 \\
\hline \multicolumn{6}{|l|}{ Model II } \\
\hline $\begin{array}{l}1970-80 \\
\text { Error in } \\
1970 \text { Indicators }\end{array}$ & $\begin{array}{r}.59781 \\
(.09318)\end{array}$ & $\begin{array}{r}.29915 \\
(.08507)\end{array}$ & $\begin{array}{r}.18447 \\
(.06523)\end{array}$ & -.10976 & .779 \\
\hline \multicolumn{6}{|l|}{ Model III } \\
\hline $\begin{array}{l}1960-70 \\
\text { No Error }\end{array}$ & $\begin{array}{r}.47293 \\
(.10600) \\
\end{array}$ & $\begin{array}{r}.43158 \\
(.09391) \\
\end{array}$ & $\begin{array}{r}.08157 \\
(.03972) \\
\end{array}$ & -.00558 & .856 \\
\hline
\end{tabular}

Standard errors in parentheses. 
Comparing Models I and II in Table 3 shows the effect of random measurement error on the estimating equation, since the two equations differ only in the measurement accuracy of the 1970 symptomatic data. There are noticeable differences between the two equations. Two of the coefficients (voters and enrollment) as well as the intercept change considerably. Furthermore, the amount of explained variance is substantially reduced when poorly measured variables are used to estimate the equation.

It has been established that the estimating equation contains a significant amount of coefficient drift and that poorly measured independent variables do affect the estimated regression coefficients. The question now addressed is what impact coefficient drift, biased regression estimators as well as random measurement error in the postcensal symptomatic indicators have on estimate accuracy. To ascertain estimate accuracy, four measures will be presented: the average absolute percent error (AAPE), the number of counties with errors greater than 5 percent and 10 percent and the index of misallocation (IOM) (Spar and Martin, 1980; Zitter and Word, 1971). The first three measures are fairly straightforward, while the IOM is interpreted as the percentage of the population that has been misallocated in the estimation process (Swanson, 1981).

Table 4 contains measures of estimate error for all six tests. As one expects, Test I results in the most accurate set of estimates, with an AAPE of 2.8 percent and a misallocation of only 0.87 percent of the state's population. Examination of the result of Test $V$ indicates the effect of coefficient drift is rather small. This test produces estimates which are only slightly less accurate than Test I, with an AAPE of 3.0 and an IOM of .97.

Several observations are evident when comparing the errors in Tests II and III. Introduction of measurement error into the estimating equation (Test III) has only a small impact on error transmitted to the estimate. Its AAPE increases only .13 of a percentage point over that of Test I and contributes slightly less error than the introduction of coefficient drift (Test V). Measurement error in the post-censal symptomatic indicators (Test II) has, by far, the greatest negative impact on estimate accuracy. Its AAPE is almost one percentage point higher than that of Test I and contributes considerably more to estimate error than either coefficient drift (Test V) or the biased estimating equation (Test III).

Test VI has the greatest impact on estimate error because it contains both coefficient drift and measurement error in the postcensal symptomatic data. Tests IV and VI suggest that the impact on estimate error, from coefficient drift, biased regression estimators and postcensal symptomatic data measurement error, is additive. That is, the error from one source does not negate or counteract the additional error introduced by another source. The combined effect on estimate error is approximately equal to the sum of the errors due to each component separately. Test IV, which contains both effects of measurement error, has an AAPE that is larger than that found in Test II by roughly the amount of additional error found in Test III. This pattern is also found when Test VI (both postcensal measurement

Table 4

Measures of Total Population

Estimate Error for the Six Tests ${ }^{\mathrm{a}}$

\begin{tabular}{|c|c|c|c|c|c|c|}
\hline \multirow[b]{2}{*}{$\begin{array}{l}\text { Error } \\
\text { Measures }\end{array}$} & \multicolumn{2}{|c|}{ Model I } & \multicolumn{2}{|c|}{ Model II } & \multicolumn{2}{|c|}{ Model III } \\
\hline & $\begin{array}{c}\text { Test } \\
\text { I }\end{array}$ & $\begin{array}{c}\text { Test } \\
\text { II }\end{array}$ & $\begin{array}{l}\text { Test } \\
\text { III }\end{array}$ & $\begin{array}{c}\text { Test } \\
\text { IV }\end{array}$ & $\begin{array}{c}\text { Test } \\
\text { V }\end{array}$ & $\begin{array}{c}\text { Test } \\
\text { VI }\end{array}$ \\
\hline $\begin{array}{l}\mathrm{AAPE}^{\mathrm{b}} \\
\mathrm{IOM}^{\mathrm{c}} \\
\text { " Errors }\end{array}$ & $\begin{array}{r}2.800 \\
.877\end{array}$ & $\begin{array}{l}3.772 \\
1.125\end{array}$ & $\begin{array}{r}2.931 \\
.945\end{array}$ & $\begin{array}{l}3.914 \\
1.313\end{array}$ & $\begin{array}{r}3.012 \\
.972\end{array}$ & $\begin{array}{l}3.967 \\
1.089\end{array}$ \\
\hline $\begin{array}{l}>5 \% \\
\text { \# Errors }\end{array}$ & 6 & 11 & 6 & 14 & 6 & 11 \\
\hline$>10 \%$ & $\phi$ & 1 & $\phi$ & 2 & $\phi$ & 3 \\
\hline
\end{tabular}

aError is difference between 1980 Census and estimated total population.

${ }^{b}$ Average absolute percent error.

c Percent of the population misallocated. 
error and coefficient drift) is compared with Test V (coefficient drift) and Test II (postcensal measurement error). ${ }^{5}$

\section{Conclusions}

This research has examined the relative impact of three error sources on the accuracy of population estimates produced by the ratiocorrelation technique. These sources included: (1) temporal change in the regresssion coefficients (coefficient drift); (2) symptomatic indicator measurement error in the estimating equation; and (3) postcensal symptomatic indicator measurement error. Random measurement error was introduced into every symptomatic indicator by replacing actual data with estimates derived from ratio-correlation models that used occupied housing units as the independent variable. The analysis demonstrated that coefficient drift and measurement error in the estimating equation contributed very little to overall estimate inaccuracy. Poorly measured postcensal symptomatic indicators had, by far, the greatest impact on estimate error.

These findings call into question the prevailing thought that reducing coefficient drift represents the principal mechanism of achieving greater precision in ratio-correlation estimates. That coefficient drift contributes minimally to estimate error supports arguments advanced by Swanson and Tedrow (1984) as to why the various refinements to the ratiocorrelation model have led to only small improvements in estimate accuracy. Moreover, the additive effects of the three error sources suggest that minimizing any factor should reduce estimate error.

From an applications perspective, it would appear that greater benefit (i.e., more accuracy) can be achieved by focusing effort and resources in the area of postcensal symptomatic indicator measurement error rather than by modifying the basic ratio-correlation structure. However, the costs associated with error reduction and new data acquisition are much higher than those for developing or refining techniques that use existing data (Swanson and Tedrow, 1984). Given that resources can be dedicated to reducing measurement error, this area would appear to offer the most potential for improving overall population estimate

\section{accuracy.}

These results point to a more general observation of the ratio-correlation model. The range (one percentage point in the AAPE) between the optimal case (Test I) and the worst case (Test VI) attests to the robustness of the technique. Three significantly different estimation equations produced AAPEs that were within .2 of a percentage point of each other. Given the high degree of accuracy and robustness of the ratio-correlation method, further improvements in the accuracy of total population estimates produced with this technique are not likely to occur. More benefit might be achieved if research was directed at exploring new applications of the ratio-correlation method instead of trying to improve its accuracy in estimating total population.

Preliminary tests have shown that this method has the potential to produce accurate estimates of demographic characteristics such as age and race (Serow and Martin, 1978; Swanson, 1978b), although this application has not been thoroughly examined. Dependent variables other than population could also be estimated using the ratio-correlation technique. One indicator that comes to mind is occupied housing units. Household estimates are not only important in their own right, but any gains in their accuracy should lead to a smaller error in estimating population (Tayman, 1980).

The robustness of the ratio-correlation method and its sensitivities to error need to be examined using a variety of geographic areas, symptomatic indicators and dependent varia. bles. Simulation approaches might prove fruitful in this regard, as alternate levels of measurement error and different combinations of symptomatic indicators could be studied in a more systematic fashion.

\section{FOOTNOTES}

\footnotetext{
${ }^{1} A$ poorly measured dependent variable (population) is another potential source of error. This variable is mainly affected by differential undercount between two censuses. Since the variables are measured as ratios and not absolute numbers, identical levels of undercount between two censuses will not transmit error into the estimating equation. Moreover, the extent of differential undercount in recent censuses has been relatively minor. For most practical purposes, it can be safely assumed that effects of dependent variable measurement error will not be significant.

'Systematic error occurs in virtually all data collection activities, but it is a very difficult phenomena to study.
} 
Precise quantification of the direction and magnitude of these types of errors is not often known, and no general statistical theory or empirical models can be developed for systematic error (Vehikanov, 1965:66). Symptomatic indicators usually come from well designed and controlled data collection systems (e.g., vital registration, school enrollment). Any biases are likely to occur to the same degree in all of the units for which the data is collected (e.g., counties). This would not affect the ratio-correlation estimates, since the variables are measured as ratios of proportions. Moreover, probability sampling schemes often used to collect symptomatic variables introduce random error into these data. Therefore, it seems appropriate to treat errors in the symptomatic data as random.

${ }^{8}$ For sake of brevity, these results are not presented. They are available, for interested readers, from the authors.

The same procedures described earlier, applied to these equations, did not reveal any violations of the regression model assumptions.

'Similar patterns were observed when the poorly measured variables were entered separately. The introduction of the most accurately measured variable (voters), by itself, hardly altered the AAPE in Model III and only reduced the AAPE in Model II by .1 of a percentage point.

\section{REFERENCES}

Anscombe, F. and J. Tukey. 1963. "The Examination and Analysis of Residuals." Technometrics 5(2):141-160.

Bousfield, M. 1977. "Intercensal Estimation Using a Current Sample and Census Data." Review of Public Data Use 5:6-15.

Beasley, D., E. Kuh and R. Welsch. 1980. Regression Diagnostics: Identifying Influential Data and Sources of Collinearity. New York: John Wiley and Sons.

Blalock, H. 1972. Social Statistics. New York: McGraw-Hill.

Chatterjee, S. and B. Price. 1977. Regression Analysis by Example. New York: John Wiley and Sons.

Chow, G. 1960. "Tests of Equality Between Sets of Coefficients in Two Linear Regressions." Econometrica 28:591-605.

D'allesandro, F. and J. Tayman. 1981. "Ridge-Regression for Population Estimation: Some Insights and Clarifications." Paper presented at the annual meeting of the Population Association of America, Washington, D.C.

Draper, N. and H. Smith. 1981. Applied Regression Analysis, 2nd Edition. New York: John Wiley and Sons.

Ericksen, E. 1974. "A Regression Method for Estimating Population Change in Local Areas." Journal of the American Statistical Association 69:867-875.

1973. "A Method for Combining Sample Survey Data and Symptomatic Indicators to Obtain Population Estimates for Local Areas." Demography 10:137-160.

Espenshade, T. and J. Tayman. 1982. "Confidence Intervals for Postcensal State Population Estimates." Demography 19(2):191-210.

Goldberg, D. and T. Balakrishnan. 1960. "A Partial Evaluation of Four Estimation Techniques." Paper presented at the Annual Meeting of the American Statistical Association.

Goldberg, D., V. Rao and K. Namboodiri. 1964. "A Test of the Accuracy of the Ratio-Correlation Population Estimates." Land Economics 40:100-102.

Goldfield, S. and R. Quandt. 1972. Nonlinear Methods in Econometrics. Amsterdam: North Holland Publishing Company.
Gujarati, J. 1978. Elementary Econometrics. New York: McGraw-Hill.

Kmenta, J. 1971. Elements of Econometrics. New York: Macmillan and Company.

Mandell, M. and J. Tayman. 1982. "Mensuring Temporal Stability in Regression Models of Population Estimation." Demography 19(1):135-146.

Namboodiri, K. 1972. "On the Ratio-Correlation and Related Methods of Subnational Population Estimation." Demography 9(3):443-454.

. and N. Lalu. 1971. "The Average of Several Regression Estimates as an Alternative to the Multiple Regression Estimate in Postcensal and Intercensal Estimates: A Case Study." Rural Sociology 36:187-194.

O'Hare, W. 1980. "A Note on the Use of Regression Methods for Making Population Estimates." Demog. raphy 17(3)341-343.

1976. "A Report on a Multiple Regression

Method for Making Population Estimates." Demography 13(3):369-380.

Park, R. 1966. "Estimation With Heteroscedastic Error Terms." Econometrica 34(4):888.

Pursell, D. 1970. "Improving Population Estimates with the Use of Dummy Variables." Demography 7(1):87-92.

Rosenberg, H. 1968. "Improving Current Population Estimates Through Stratification." Land Economics 44:331-338.

Schmitt, R. and J. Grier. 1966. "A Method for Estimating the Population of Minor Civil Divisions." Rural Sociology 31:355-361.

and A. Crosetti. 1954. "Accuracy of the Ratio-Correlation Method for Estimating Postcensal Population." Land Economics 30:279-281.

Serow, W. and J. Martin. 1978. "Estimating Demographic Characteristics Using the Ratio-Correlation Method." Demography 15(2):223-233.

Sly, D. and J. Tayman. 1980. "Metropolitan Morphology and Population Mobility: The Theroy of Ecological Expansion Reexamined." American Journal of Sociology 86(1):119-138.

Spar, M. and J. Martin. 1980. "Evaluating Postcensal Population Estimates." Paper presented at the annual meeting of the Southern Regional Demographic Group, Tallahassee, Florida.

1979. "Refinements to Regression Based Estimates of Postcensal Population Characteristics." Review of Public Data Use 7, No. 5/6.

Swanson, D. 1981. "Allocation Accuracy in Population Estimates: An Overlooked Criteria with Fiscal Implications." Small Area Population Estimates, Methods and Their Accuracy and New Metropolitan Area Definitions and Their Impact on the Private and Public Sector, Series GE-11, No. 7, U.S: Bureau of the Census. Washington, D.C. 1980. "Improving Accuracy in Multiple Regression Estimates of Population Using Principles from Causal Modelling." Demography 17(4):413-427. 1978a. "Preliminary Results of an Evaluation of the Utility of Ridge-Regression for Making County Population Estimates." Paper presented at the annual meeting of the Pacific Sociological Association, Spokane, Washington.

1978b. "An Evaluation of Ratio and Difference Regression Models for Estimating Small Highly Concentrated Population: The Case of Ethnic Groups." Review of Public Data Use 6:18-27.

and L. Tedrow. 1984. "Improving the Measurement of Temporal Change in Regression Models Used for County Population Estimates." 
Demography 21(3):373-382.

Tayman, J. 1980. "Total and Occupied Units as Useful Symptomatic Indicators in Population Estimation Models." Paper presented at the Federal-State Population Cooperative Meeting, Denver, Colorado.

U.S. Bureau of the Census. 1973. "State Cooperative Program for Local Population Estimates: Test ResultsApril 1, 1970." Current Population Reports, Series P-26, No. 21.

Velikanov, M.A. 1965. Measurement Errors and Empirical
Relations. Israel Program for Scientific Translations. Jerusalem.

Zitter, M. and H. Shryock. 1964. "Accuracy of Methods for Preparing Postcensal Population Estimates for Local Areas." Demography 1:227-241.

and D. Word. 1971. "Did Intercensal Estimates Go Wrong in the 1960's: A View from the National Level." Paper presented at the annual meeting of the American Statistical Association, Fort Collins, Colorado. 